\title{
Is pathological aging a successful resistance against amyloid-beta or preclinical Alzheimer's disease?
}

\author{
Melissa E Murray* and Dennis W Dickson
}

\begin{abstract}
Individuals with pathological aging, a form of cerebral amyloidosis in older people, have widespread extracellular amyloid-beta (Aß) senile plaque deposits in the setting of limited neurofibrillary tau pathology. Unlike the characteristic finding of antemortem cognitive impairment in Alzheimer's disease patients, individuals with pathological aging usually lack cognitive impairment despite similar $A \beta$ senile plaque burdens. It has been hypothesized that protective or resistance factors may underlie pathological aging, thus minimizing or preventing deleterious effects on cognition. Despite increasing interest and recognition, a review of the literature remains challenging given the range of terms used to describe pathological aging. This debate briefly reviews neuropathologic and biochemical evidence that pathological aging individuals have resistance factors to $A \beta$ plaque pathology. Additionally, we will discuss evidence of pathological aging as an intermediate between normal individuals and Alzheimer's disease patients, and discuss protective or resistance factors against vascular disease and neurofibrillary pathology. Lastly, we will emphasize the need for longitudinal biomarker evidence using amyloid positron emission tomography, which will provide a better understanding of the kinetics of $A \beta$ deposition in pathological aging.
\end{abstract}

\section{Introduction}

Histopathologic changes characteristic of Alzheimer's disease $(\mathrm{AD})$ have been described in nondemented older individuals [1-7], with particular focus on a form of senile cerebral amyloidosis - termed pathological aging. The neuropathologic characteristics of pathological aging are extracellular amyloid-beta $(A \beta)$ in senile plaques [8] and intracellular tau in neurofibrillary tangles and neuropil threads. In $\mathrm{AD}$ these lesions are accompanied by dendritic and synaptic abnormalities, as well as neuronal loss. In pathological aging, however, significant $A \beta$ deposits (sufficient for a neuropathologic diagnosis of AD using Khachaturian criteria [9]) are detected in the setting of minimal cortical and limbic neurofibrillary pathology [2].

Pathological aging is usually a finding in older individuals who have no significant antemortem cognitive impairment, and some individuals may even be high functioning. Whether it is preclinical AD is controversial. Without longitudinal biomarker evidence to ascertain the

\footnotetext{
* Correspondence: murray.melissa@mayo.edu

Department of Neuroscience, Mayo Clinic, 4500 San Pablo Road, Jacksonville, FL 32224, USA
}

timing of amyloid deposition, it is uncertain how long amyloid deposits have been present in the brains of individuals with pathological aging. Recently, it was suggested that such individuals may have protective or resistance factors against the neuronal and synaptic pathology, which are structural correlates with cognitive impairment. While increasingly recognized, there is a range of terms for pathological aging that makes review of the literature challenging, including presymptomatic or incipient $\mathrm{AD}$ [4], preclinical AD [6], pathological AD [7], nondemented high pathology controls [3], asymptomatic persons with $\mathrm{AD}$ neuropathology [10], intermediate probability mismatches [11], and pathologically preclinical $\mathrm{AD}$ [5]. This debate will briefly review the evidence for and against the notion that pathological aging is a state of resilience from the putative toxic effects of $\mathrm{A} \beta$.

\section{Evidence supporting a resistance to amyloid-beta in pathological aging}

Some of the strongest data that support the hypothesis of a resistance factor in pathological aging come from neuropathologic and biochemical studies. Early investigations of

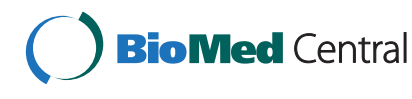

C 2014 Murray and Dickson; licensee BioMed Central Ltd. The licensee has exclusive rights to distribute this article, in any medium, for 12 months following its publication. After this time, the article is available under the terms of the Creative Commons Attribution License (http://creativecommons.org/licenses/by/4.0), which permits unrestricted use, distribution, and reproduction in any medium, provided the original work is properly credited. The Creative Commons Public Domain Dedication waiver (http://creativecommons.org/publicdomain/zero/1.0/) applies to the data made available in this article, unless otherwise stated. 
pathological aging revealed that although senile plaque density was sufficient for $\mathrm{AD}$ according to Khachaturian criteria [9], morphologic and immunohistochemical differences existed between $A \beta$ deposits in pathological aging and AD. Diffuse plaques, principally composed of A 342 [12], were more abundant in pathological aging, and paired helical filament tau immunoreactivity or glial reaction was rarely observed in proximity to senile plaques $[2,4]$. Moreover, $A \beta$ deposits in pathological aging had less codeposition of apolipoprotein $\mathrm{E}$ and the individuals had less advanced glycation end product immunoreactivity $[13,14]$. Biochemical analyses of $\mathrm{A} \beta$ peptides in pathological aging and AD revealed overlapping profiles [15]. Subtle quantitative differences were noted, but evidence from mass spectrometry identified more amino-terminal truncations in $\mathrm{A} \beta$ of $\mathrm{AD}$ compared with pathological aging. $A \beta 42$ levels, however, have been found elevated in pathological aging compared with $\mathrm{AD}[3,15]$, which probably represents greater abundance of diffuse plaques in pathological aging [12].

Oligomeric assemblies of soluble $A \beta$ pools were not different, but insoluble $A \beta$ - particularly $A \beta$ in formic acid and guanidine hydrochloride extracts - better distinguished pathological aging from AD. The data supported previous findings from a study investigating neuropathologic and biochemical differences in the oldest old, which evaluated nondemented pathological aging (referred to as high pathology controls) [3]. When compared with an age-matched, demented $\mathrm{AD}$ cohort, soluble oligomeric assemblies were not found to differ. A recent study evaluating differences in normal individuals, pathological aging (referred to as intermediate probability mismatches), and AD confirmed these findings [11], but added new information suggesting that $\mathrm{A} \beta$ oligomeric monomers and dimers in synaptoneurosomes may be lower in nondemented pathological aging compared with demented $\mathrm{AD}$. Using array tomography to visualize and quantify synaptic densities near amyloid deposits in AD, Koffie and colleagues provide evidence for deleterious effects of oligomeric $A \beta$ [16]. They further show that synapse loss is exacerbated in apolipoprotein E $\varepsilon 4$ carriers, who also had higher levels of oligomeric $A \beta$. Given the extensive overlap between $\mathrm{AD}$ and pathological aging with respect to soluble oligomeric assemblies [15], but reportedly greater synaptophysin and neprilysin levels in pathological aging [17], an unknown resistance factor may mitigate the effects of oligomeric $A \beta$ species on synaptic pathology.

\section{Evidence opposed to a resistance to amyloid-beta in pathological aging}

Early biochemical studies evaluating insoluble and soluble $A \beta 40$ and $A \beta 42$ provide evidence for an alternative hypothesis - that pathological aging is merely a transitional state between normal aging and $\mathrm{AD}$ [18]. Using an enzyme-linked immunosorbent assay to measure pools of $A \beta$, the largest soluble $A \beta 1-40$ and $A \beta 1-42$ pools were found in the brains of nondemented normal individuals (50\% and $23 \%$, respectively), and the smallest fraction was found in demented AD brains (2.7\% and 0.7\%). Soluble $A \beta 1-40$ and $A \beta 1-42$ were intermediate in nondemented pathological aging ( $8 \%$ and $0.8 \%$, respectively), whereas the insoluble $\mathrm{A} \beta 1-40$ pool in $\mathrm{AD}$ was found to be 20 -fold higher than in pathological aging brains.

Rather than a resistance factor to $A \beta$, a third hypothesis postulates that factors other than $A \beta$ mediate cognitive deficits in $\mathrm{AD}$, most notably effects of cerebrovascular disease and neurofibrillary tau pathology. When comparing $\mathrm{AD}$ with pathological aging, white matter rarefaction and cerebral amyloid angiopathy were found to be more severe in $\mathrm{AD}$ [3]. These findings suggest that white matter pathology associated with reduced perfusion due to cerebral microvasculature dysfunction may contribute to differences in cognitive dysfunction between the two groups. Although inherent to the classification of pathological aging, less neurofibrillary pathology was shown to correlate with better cognitive performance in pathological aging (referred to as asymptomatic persons with AD neuropathology) [10]. Lower vascular risk and older age were also found to associate with pathological aging compared with demented $A D$ patients. Further supporting this third hypothesis, a recent study investigating a nondemented cohort found that vascular risk factors (for example, diabetes, hypertension) influenced the relationship among memory, cortical thickness, and $A \beta$ as measured using $\left[{ }^{11} \mathrm{C}\right]$ Pittsburgh compound $\mathrm{B}$ positron emission tomography [19].

\section{Explanations for conflicting evidence}

One of the largest hurdles in addressing this controversy is the different constructs used by various investigators to describe pathological aging. Each of the three hypotheses presented was based on data that did not conflict as much as provide supportive evidence that multiple factors contribute to cognitive deficits associated with $A D$ pathology. In understanding the significance of $A \beta$ in cognitively normal individuals, it is important to consider that death due to intercurrent illnesses (for example, cancer, heart disease, respiratory infection) may truncate the disease process at a point where it is impossible to know whether dementia would have been the ultimate outcome had accumulation of $A \beta$ led to neuronal and synaptic damage. Without knowledge of the kinetics of amyloid deposition in pathological aging, it will be difficult to determine whether there are actually factors that confer protection (for example, genetic variants, cognitive reserve) to toxic effects of $A \beta$ accumulation. 


\section{Conclusion}

The main issue one should consider is where patients with pathological aging lie in the course of amyloid deposition, whether this is an acute process or one that has been playing out over a number of years. Efforts have been made to establish the age of $A \beta$ proteins through investigations into post-translational modifications such as N-terminal degradation, racemization, isomerization, oxidation, pyroglutamyl formation, and covalently linked dimers [20,21]. Neuropathologic studies can classify $\mathrm{A} \beta$, tau and other co-existing pathologies, but it is not yet possible to determine with certainty the age at which $\mathrm{A} \beta$ deposition began in an individual patient. Through the use of longitudinal amyloid positron emission tomography imaging, we will be able to better address whether pathological aging patients are resistant to the deleterious effects of long-standing $A \beta$ deposition.

\section{Abbreviations}

AD: Alzheimer's disease; A $\beta$ : Amyloid-beta.

\section{Competing interests}

The authors declare that they have no competing interests.

\section{Acknowledgements}

This debate was supported by NIH grants: Mayo Alzheimer Disease Research grant (P50 AG016574) and Mayo Clinic Study on Aging (U01 AG006786). The authors acknowledge the Robert E. Jacoby Professorship for Alzheimer's Research.

\section{Published: 06 May 2014}

References

1. Braak H, Braak E: Neuropathological stageing of Alzheimer-related changes. Acta Neuropathol 1991, 82:239-259.

2. Dickson DW, Crystal HA, Mattiace LA, Masur DM, Blau AD, Davies P, Yen SH, Aronson MK: Identification of normal and pathological aging in prospectively studied nondemented elderly humans. Neurobiol Aging 1992, 13:179-189.

3. Maarouf CL, Daugs ID, Kokjohn TA, Walker DG, Hunter JM, Kruchowsky JC, Woltjer R, Kaye J, Castano EM, Sabbagh MN, Beach TG, Roher AE: Alzheimer's disease and non-demented high pathology control nonagenarians: comparing and contrasting the biochemistry of cognitively successful aging. PLoS One 2011, 6:e27291.

4. Morris JC, Storandt M, McKeel DW Jr, Rubin EH, Price JL, Grant EA, Berg L: Cerebral amyloid deposition and diffuse plaques in 'normal' aging: evidence for presymptomatic and very mild Alzheimer's disease. Neurology 1996, 46:707-719.

5. Rijal Upadhaya A, Kosterin I, Kumar S, von Arnim CAF, Yamaguchi H, Fändrich $M$, Walter J, Thal DR: Biochemical stages of amyloid- $\beta$ peptide aggregation and accumulation in the human brain and their association with symptomatic and pathologically preclinical Alzheimer's disease. Brain 2014, 137:887-903.

6. Schmitt FA, Davis DG, Wekstein DR, Smith CD, Ashford JW, Markesbery WR 'Preclinical' AD revisited: neuropathology of cognitively normal older adults. Neurology 2000, 55:370-376

7. Shankar GM, Li S, Mehta TH, Garcia-Munoz A, Shepardson NE, Smith I, Brett FM, Farrell MA, Rowan MJ, Lemere CA, Regan CM, Walsh DM, Sabatini BL, Selkoe DJ: Amyloid-beta protein dimers isolated directly from Alzheimer's brains impair synaptic plasticity and memory. Nat Med 2008, 14:837-842.

8. Dickson DW: The pathogenesis of senile plaques. J Neuropathol Exp Neurol 1997, 56:321-339.

9. Khachaturian ZS: Diagnosis of Alzheimer's disease. Arch Neurol 1985, 42:1097-1105.
10. Monsell SE, Mock C, Roe CM, Ghoshal N, Morris JC, Cairns NJ, Kukull W: Comparison of symptomatic and asymptomatic persons with Alzheimer disease neuropathology. Neurology 2013, 80:2121-2129.

11. Perez-Nievas BG, Stein TD, Tai HC, Dols-Icardo O, Scotton TC, Barroeta-Espar I, Fernandez-Carballo L, de Munain EL, Perez J, Marquie M, Serrano-Pozo A, Frosch MP, Lowe V, Parisi JE, Petersen RC, Ikonomovic MD, Lopez OL, Klunk W, Hyman BT, Gomez-Isla T: Dissecting phenotypic traits linked to human resilience to Alzheimer's pathology. Brain 2013, 136:2510-2526.

12. Iwatsubo T, Odaka A, Suzuki N, Mizusawa H, Nukina N, Ihara Y: Visualization of $A \beta 42(43)$ and $A \beta 40$ in senile plaques with end-specific $A \beta$ monoclonals: evidence that an initially deposited species is Aß42(43). Neuron 1994 , 13:45-53.

13. Dickson DW: Senile cerebral amyloidosis (pathological aging) and cognitive status predictions: a neuropathology perspective. Neurobio/ Aging 1996, 17:936-937. discussion 945-947.

14. Dickson DW, Ivanushkin A, Heitner J, Yen S-H: Apolipoprotein E Immunoreactivity is Increased in Amyloid Deposits of Alzheimer's Disease, but not Pathological Aging or Diffuse Lewy Body Disease. In Research Advances in Alzheimer's Disease and Related Disorders. Edited by lqbal K. Chichester: Wiley; 1995:371-383

15. Moore BD, Chakrabarty $P$, Levites $Y$, Kukar TL, Baine AM, Moroni T, Ladd TB, Das $P$, Dickson DW, Golde TE: Overlapping profiles of $A \beta$ peptides in the Alzheimer's disease and pathological aging brains. Alzheimers Res Ther 2012, 4:18

16. Koffie RM, Hashimoto T, Tai HC, Kay KR, Serrano-Pozo A, Joyner D, Hou S, Kopeikina KJ, Frosch MP, Lee VM, Holtzman DM, Hyman BT, Spires-Jones TL: Apolipoprotein E4 effects in Alzheimer's disease are mediated by synaptotoxic oligomeric amyloid-beta. Brain 2012, 135:2155-2168.

17. Wang DS, Lipton RB, Katz MJ, Davies P, Buschke H, Kuslansky G, Verghese J, Younkin SG, Eckman C, Dickson DW: Decreased neprilysin immunoreactivity in Alzheimer disease, but not in pathological aging. J Neuropathol Exp Neurol 2005, 64:378-385.

18. Wang J, Dickson DW, Trojanowski JQ, Lee VM: The levels of soluble versus insoluble brain $A \beta$ distinguish Alzheimer's disease from normal and pathologic aging. Exp Neurol 1999, 158:328-337.

19. Villeneuve S, Reed BR, Wirth M, Haase CM, Madison CM, Ayakta N, Mack W Mungas D, Chui HC, Decarli C, Weiner MW, Jagust WJ: Cortical thickness mediates the effect of beta-amyloid on episodic memory. Neurology 2014, 82:761-767.

20. Shapira R, Austin GE, Mirra SS: Neuritic plaque amyloid in Alzheimer's disease is highly racemized. J Neurochem 1988, 50:69-74.

21. Roher AE, Lowenson JD, Clarke S, Wolkow C, Wang R, Cotter RJ, Reardon IM, Zurcher-Neely HA, Heinrikson RL, Ball MJ, Greenberg BD: Structural alterations in the peptide backbone of beta-amyloid core protein may account for its deposition and stability in Alzheimer's disease. J Biol Chem 1993 268:3072-3083.

10.1186/alzrt254

Cite this article as: Murray and Dickson: Is pathological aging a successful resistance against amyloid-beta or preclinical Alzheimer's disease? 2014, 6:24 